\title{
KOMPOSISI PORTRAIT LANDSCAPE DENGAN OBJEK PEMANDANGAN PADA 12 LOKASI DI BALI
}

\author{
Onkky Wahyu Al Pratama, R. Sulistiyo Wibowo \\ Program Studi Fotografi, Jurusan Penerbitan \\ Politeknik Negeri Media Kreatif Jakarta
}

\begin{abstract}
Abtract
Landscape portrait concept is not new, but in its application and use, including rare. In landscape photography, many photographers featuring views of the widest-shaped or landscape (horizontal) and rarely use the portrait (vertical). The research questions are how photographing landscape portrait composition, whether landscape portrait composition can enrich the composition of the landscape, and how the outcome of portrait landscape that can be enjoyed in general. The methods used are observation, exploration on the method of creation, experiment or improvisation, embodiment, and presentation of work. The sceneries in Bali have been selected to provide the different compositions using landscape portrait composition. In photographing the landscape portrait, photographers should use good composition, as in the portrait landscape use good composition can provide the depth dimension of the photograph, so the photos taken can still be attractive at first sight.
\end{abstract}

Keywords: photography, composition, portrait, landscape

\section{PENDAHULUAN}

Fotografi berasal dari kata
photos yang artinya sinar dan graphos yang artinya menggambar atau melukis. Dapat diartikan fotografi adalah suatu proses menggambar dengan menggunakan sinar dan menghasilkan sebuah gambar yang biasa disebut dengan foto. Terdapat banyak cabang atau aliran fotografi yang dapat dieksplorasi lebih jauh lagi dalam dunia fotografi salah satunya adalah aliran fotografi landscape.

Konsep portrait landscape bukan sesuatu hal yang baru, tetapi dalam penerapannya dan pemakaiannya termasuk jarang.
Dalam fotografi landscape banyak fotografer yang menampilkan pemandangan yang seluas-luasnya atau yang berbentuk landscape (horizontal) dan jarang menggunakan portrait (vertikal) dalam landscapenya. Landscape berbentuk portrait memiliki banyak aturan yang digunakan agar tetap terlihat keindahan alamnya dengan banyak bermain komposisi rule of third, komposisi garis, komposisi framing, dan menggunakan objek-objek sekitar lokasi untuk mendukung pemandangannya agar lebih enak untuk dilihat. Bisa dibilang hanya $10-15 \%$ saja foto-foto yang masuk dalam kategori landcsape yang 
berformat "Portrait" (Yadi Yasin: 2009). Dalam portrait landscape juga memberikan suatu tantangan tersendiri bagi fotografer karena dapat melihat pemandangan dengan sudut sempit atau sebagian dari luasnya pemandangan tersebut.

Pemandangan yang berada di

Bali dipilih karena dapat memberikan sisi komposisi yang berbeda dengan menggunakan komposisi portrait landscape. Di pulau Bali terdapat banyak pemandangan yang tak kalah indahnya dengan yang dimiliki negara lain. Pulau ini setiap tahunnya banyak dikunjungi para wisatawan baik lokal maupun mancanegara. Karena keindahannya yang tak ada habisnya itulah membuat pulau ini cocok menjadi lokasi objek. Berdasarkan latar belakang maka penelitian ini membahas cara memotret landscape dengan komposisi portrait, alasan komposisi portrait landscape dapat memperkaya komposisi dalam landscape, dan hasil akhir dari portrait landscape agar bisa dinikmati secara umum.

Sukarya (2009:11), fotografi adalah sebuah seni melihat. Karena fotografi mengajarkan pada kita cara yang unik dalam melihat dunia dan sekaligus memberikan penyatum kembang rumput di tepi lubuk, atau pada kerapuhan lingkungan hidup di mana kita semua menjadi bagian yang tidak terpisahkan. Sementara Noel \& Yoels (2013:4) menjelaskan bahwa fotografi bisa diartikan seni merekam atau mengambil gambar berdasarkan pencahayaan menggunakan alat yang disebut kamera. Dari kedua definisi di atas, dapat disimpulkan bahwa definisi fotografi adalah cara unik melihat dunia dengan menuangkan kejujuran yang dilihat oleh mata dan divisualkan dalam foto.

Fotografi landscape dapat dijadikan penyaluran hobi atau bakat seseorang dalam fotografi untuk mengabadikan keindahan alam yang ada, tidak hanya mengabadikannya saja fotografi landscape juga dapat memanjakan mata untuk melihat objek pemandangan yang difoto. "fotografi landscape adalah gambaran foto pegunungan hijau yang indah, laut biru yang luas, langit biru dengan awan yang berarak, keindahan panorama perkotaan dengan gedung-gedung yang unik dan lampu-lampu yang indah di senja hari atau istilahnya cityscape, landscape sebuah lokasi pertambangan dan lainnya" Edison Paulus, 2013:2).

Foto pemandangan dapat di kategorikan menjadi beberapa macam yaitu: (1) Foto Landscape adalah foto pemandangan alam daratan yang terdiri dari alam pegunungan, lembah, persawahaan, dan lain-lain. (2) Foto Seascape adalah foto pemandangan laut yang terdiri dari alam lautan, danau, dan segala obyek yang menekankan keberadaan air. (3) Foto Skyscape adalah foto pemandangan langit yang terdiri dari keberadaan awan, biru langit, sunrise, sunset, dan lain-lain. (4) Foto Cityscape adalah foto 
pemandangan kota atau pedesaan yang terdiri dari keunikan dan keindahan dari sudut-sudut perkotaan ataupun pedesaan yang mampu menginformasikan ciri khas kehidupan masyarakat didalamnya.

Format vertikal atau portrait adalah komposisi dalam fotografi yang lebih sering dipakai untuk pengambilan foto manusia seperti foto model, profile, dan human interest. Tidak hanya manusia saja, tetapi foto produk, hewan, macro, landscape juga dapat memakai format vertikal atau portrait ini pada komposisinya. Dalam komposisi tidak hanya ada format vertikal atau portrait tetapi ada format horizontal atau landscape, perbedaan pengambilan format dapat menimbulkan efek berbeda pada komposisi akhir, lihatlah pada jendela bidik secara horizontal maupun vertikal.

Foto manusia juga banyak mengambil format horizontal atau landscape, tetapi lebih banyak menggunakan format vertikal atau portrait untuk lebih memberikan detail profile manusianya. Begitu juga sebaliknya dengan foto produk, hewan, macro, landscape juga banyak mengambil format vertikal atau portrait, tetapi lebih banyak menggunakan format horizontal atau landscape karena dalam foto produk saja dalam fotonya tidak hanya satu produk saja, banyak yang memilih terdapat satu paket dalam fotonya sehingga menggunakan format horizontal atau landscape untuk pengambilan fotonya sehingga lebih detail setiap produknya, karena detailnya lebih jika ada produk yang memiliki teks dan makanan untuk lebih terlihat lezatnya.

Fotografi tidak hanya sekadar memotret apa yang diinginkan selain melihat, merasakan, mengeluarkan ide kreativitas dalam foto. Dalam fotografi, ada komposisi yang membuat foto lebih seimbang dalam gelap terang, bentuk, warna, garis, dan lain sebagainya. Berikut adalah definisi komposisi menurut beberapa ahli.

Sukarya (2009:31), komposisi adalah seni untuk menciptakan harmoni pembagian bidang dengan memanfaatkan berbagai elemen visual yang tersedia: alur garis, bentuk, cahaya, bayangan, warna, dan tekstur.

Menurut Edison Paulus (2013:15), komposisi adalah teknik menata beragam elemen dalam bidang gambar (foto) menjadi sesuatu yang indah yang dapat menarik perhatian. Menurut Atok Sugiarto (2006:7), komposisi adalah tindakan seni atau cara merangkai, menata, dan membuat berbagai unsur yang hendak ditampilkan dalam suatu gambar menjadi tampilan yang baik, menarik, dan enak dilihat.

Dengan komposisi juga dapat menghasilkan visual yang dapat menyampaikan perasaan yang diinginkan untuk berekspresi dalam foto. Dengan demikian perlu menata komposisi sedemikian rupa agar tujuan tercapai, apakah itu untuk menyampaikan kesan diam atau sesuatu mengejutkan, dan beda. 
Dalam komposisi selalu ada satu titik perhatian yang pertama menarik perhatian. Hal ini terjadi karena penataan posisi, kontras cahaya subjek dibandingkan sekitarnya yang membentuk arah yang membawa perhatian pengamat pada satu titik.

Berikut ini adalah beberapa jenis komposisi yang dapat digunakan: (1) Framing adalah komposisi dimana objek utama yang mejadi point of interest. Komposisi rule of third atau aturan komposisi sepertiga bagian adalah komposisi yang umum dipakai, komposisi ini didapat dari hasil pembagian garis-garis yang akan membentuk tiga persegi panjang sama besar baik horizontal atau vertikal. (3) Garis dalam komposisi dapat menjadikan kedalaman ruangan pada foto dan mengarahkan kita pada point of interest pada objek utama juga dapat memberikan kesan dinamis pada foto. (4) Proporsi empat persegi panjang pada viewfinder memungkinkan untuk melakukan pemotretan dalam format landscape/horizontal dan vertikal/portrait. (5) Komposisi pattern berupa pengulangan pada warna, garis, dan bentuk yang keberadaan pengulangannya dapat menimbulkan kesan harmoni dan keselarasan pada sebuah foto.

Portrait landscape atau portscape adalah usaha mendapatkan kedalaman ruang (depth of field) dari sepenggal landcsape view (Yadi Yasin: 2009). Bagi sebagian orang mengetahui bahwa memotret landscape itu adalah memotret pemandangan dengan objek yang seluas-luasnya, melebar dari kiri ke kanan dan cara memotret dengan teknik panorama juga dilakukan untuk mendapatkan pemandangan yang seluas-luasnya.

Dalam mewujudkan ide karya portrait landscape, landscape yang biasanya berformat horizontal lebih banyak diambil landscape dengan format vertikal, dan perwujudannya hanya akan melihat sebagian dari luasnya objek pemandangan alam dan komposisi yang seimbang dapat memperkuat portrait landscape yang hanya menampilkan sebagian dari pemandangan alam, dengan diafragma yang kecil seperti f/8, $\mathrm{f} / 11, \mathrm{f} / 14, \mathrm{f} / 22, \mathrm{f} / 32$ dan seterusnya dapat mempertajam hasil foto., dan didukung dengan filter-filter pada lensa dapat memberikan dimensi atau efek pada foto, dan waktu yang tepat untuk memotret pemandangan itu pada saat sunrise dan setelah sunrise, begitu juga pada waktu sunset dan setelah sunset, sehingga portrait landscape tetap terjaga keindahan foto walaupun dalam format portrait atau vertikal dalam memotret landscape.

\section{METODE PENELITIAN}

1. Melalui Observasi yaitu melakukan proses memotret portrait landscape menyusun perjalanan dari satu lokasi ke lokasi lainnya itu diperlukan untuk mendapatkan lokasi yang lebih banyak dan mengetahui 
lokasi yang terdapat sunrise dan sunset .

2. Tahap Eksplorasi pada metode penciptaan yaitu:

Eksplorasi Objek

a. Dalam pemotretan portrait landscape, harus mencermati bagian pemandangan mana yang dapat di foto menjadi portrait landscape. Penggunaaan komposisi seperti rule of third, cross compose, framing, garis, pattern.

b. Objek portrait landscape yang lebih mendukung itu terdapat pada lokasi yang memiliki beberapa tempat yang lebih tinggi.

Eksplorasi Teknis

Peralatan yang mendukung dalam metode penciptaan karya foto ini adalah sebagai berikut:

b. Lensa Wide Tokina AF 11$16 \mathrm{~mm}$ for Nikon

c. Lensa Nikkor AF 18-105mm

d. Filter Hoya HD UV 77mm

e. Filter Hoya ND16 77mm

f. Filter Hoya HD UV $67 \mathrm{~mm}$

g. Filter Hoya CPL $67 \mathrm{~mm}$

h. Memory Card SD 8GB

i. Tripod

j. Laptop
k. Software Pendukung (Photoshop)

3. Eksperimen/Improvisasi yaitu (1) Eksperimen pemotretan pemandangan alam. (2) Studi dan eksperimen komposisi terhadap pemandangan alam yang akan menjadi objek pemotretan dengan studi dan percobaan penggunaan lensa.(3) Studi dan eksperimen filter CPL (Circular Polarizer) untuk memberikan warna lebih biru pada langit dan filter ND (Neutral Density) untuk teknik slow motion yang dapat memberikan efek seperti kabut saat memotret air yang bergerak seperti pantai dan air terjun. (4) Eksperimen jarak tempuh dari lokasi pertama ke lokasi berikutnya untuk mendapatkan waktu yang tepat untuk pemotretan pemandangan alam tersebut. (5) Proses pemotretan dengan portrait landscape.

4. Perwujudan yaitu proses akhir di mana sebuah karya fotografi terbentuk dari observasi, eksplorasi, dan percobaanpercobaan yang penulis lakukan dengan tujuan agar hasilnya sesuai dengan harapan. Skema proses pemotretan yang dilakukan penulis dilapangan dapat dilihat pada Gambar 1.

Setelah tahapan skema pemotretan tersebut dilalui dan mendapatkan foto yang diharapkan, maka tahap selanjutnya adalah Seleksi awal, Proses asistensi, Seleksi akhir, Pencetakan Awal (Proofing), dan Pencetakan Akhir (Pameran).

5. Penyajian Karya melalui Display dan Presentasi 


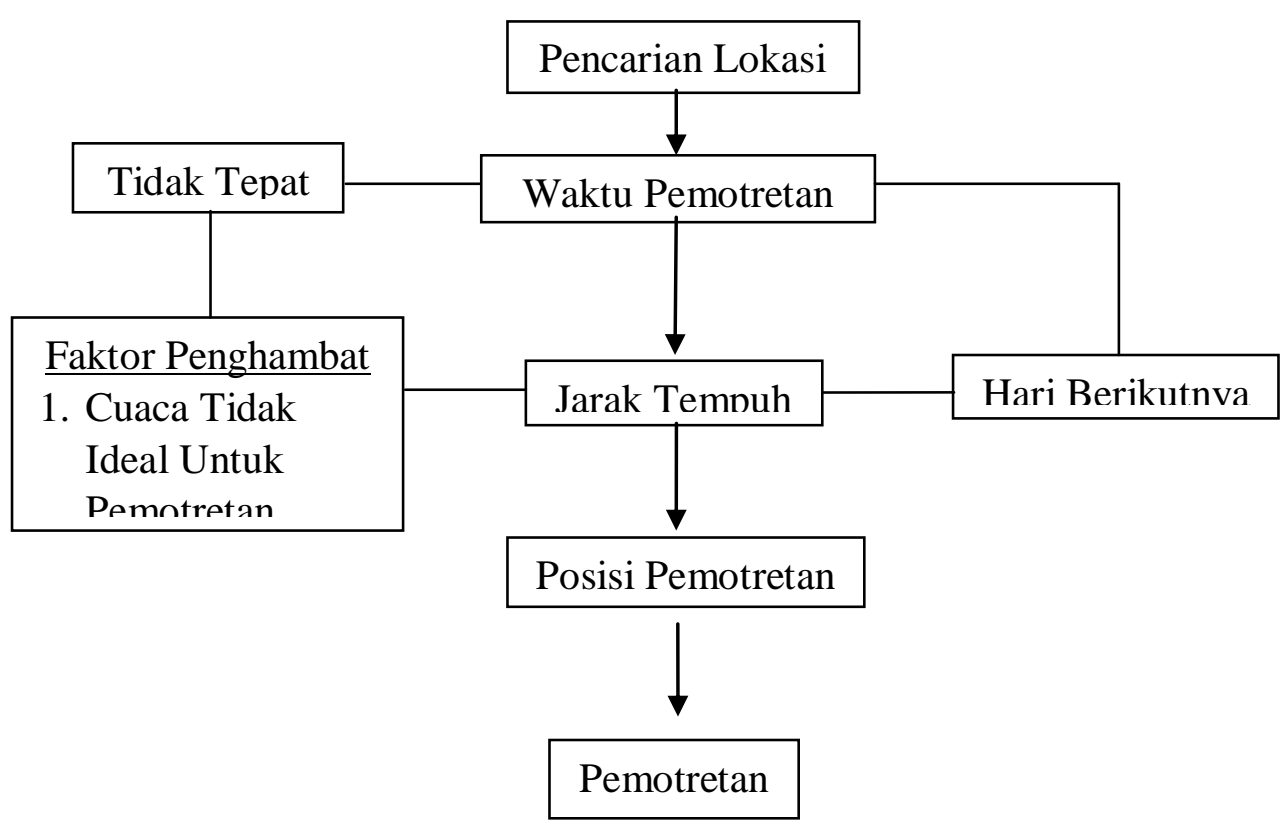

Gambar 1 Skema proses pemotretan

\section{HASIL DAN PEMBAHASAN}

\section{Karya 1 Pantai Balungan yang Tersembunyi, 2013.}

Foto ini berlokasi di pantai Balangan, Badung - Bali di sore hari. Pemotretan dengan lensa wide yang pengambilan posisi memotret berdiri di atas tebing sehingga dapat terlihat keseluruhan pemandangan pantai dari atas.

Komposisi garis dipergunakan untuk menggambarkan jauh dekat dan luasnya lokasi pemandangan, dengan diafragma yang kecil untuk mendapatkan ke tajaman foto. Nikon D90, focal length $11 \mathrm{~mm}, \mathrm{f} / 8$, speed 1/60, ISO 100.

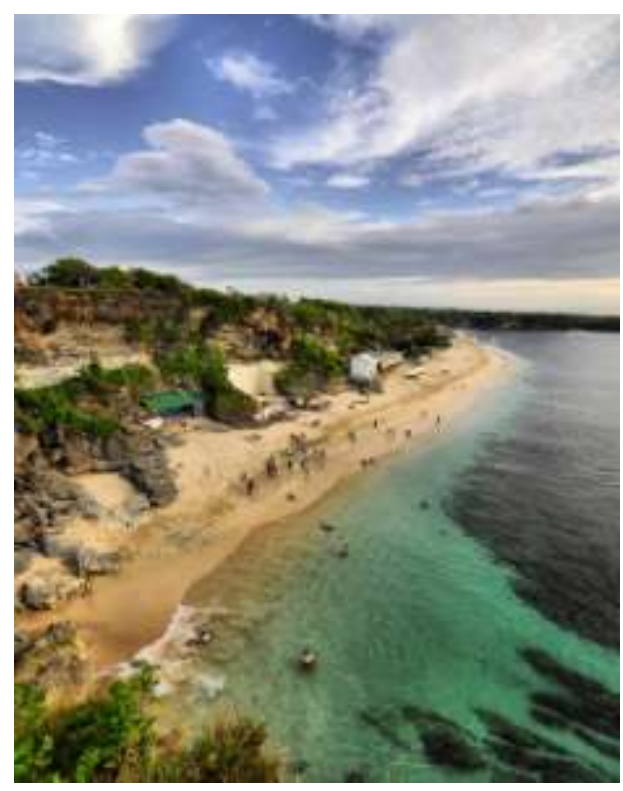

Gambar 2. Pantai Balangan yang tersembunyi 
Karya 2 Bingkai Kegelapan yang Indah, 2013

Foto ini berlokasi di Kintamani - Bali. Pemandangan yang menggambarkan silhouet gunung Batur dan pohon yang dipadukan dengan langit yang bergradasi, dengan bagian atas dan bawah sisi gelap yang membuat foto ini tampak seperti dibingkai dengan kegelapan. Pengambilan foto dilakukan pada pagi hari menjelang sunrise, menggunakan diafragma kecil untuk mempertajam foto, dan komposisi framing yang digunakan menjadikan point of interest pada gunung dan pohon. Nikon D90, focal length $16 \mathrm{~mm}, \mathrm{f} / 11$, speed 1/2, ISO 100.

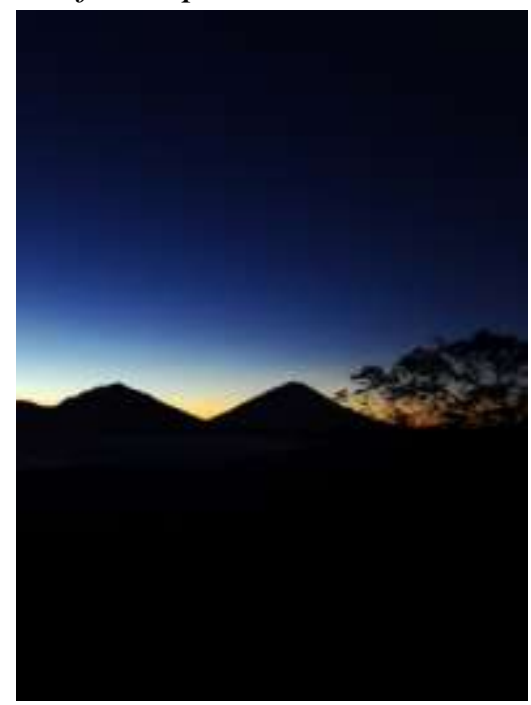

Gambar 3. Bingkai Kegelapan Yang Indah

Karya 3 Mengalir Begitu Saja, 2013

Foto ini berlokasi di air terjun Git-git, Buleleng - Bali. Foto ini menggambarkan kondisi air terjun yang dikelilingi oleh tebing berbatu dan aliran air yang begitu tenang. Teknik slow speed digunakan untuk menampilkan air pada air terjun yang sedang mengalir mengikuti jalurnya, filter yang digunakan filter ND (Neutral Density) untuk membantu teknik slow speed agar lebih menarik lagi, dan menggunakan komposisi rule of third untuk menunjukkan kedalaman ruang pada objek. Nikon D90, focal length $11 \mathrm{~mm}, \mathrm{f} / 11$, speed 30", ISO 100.

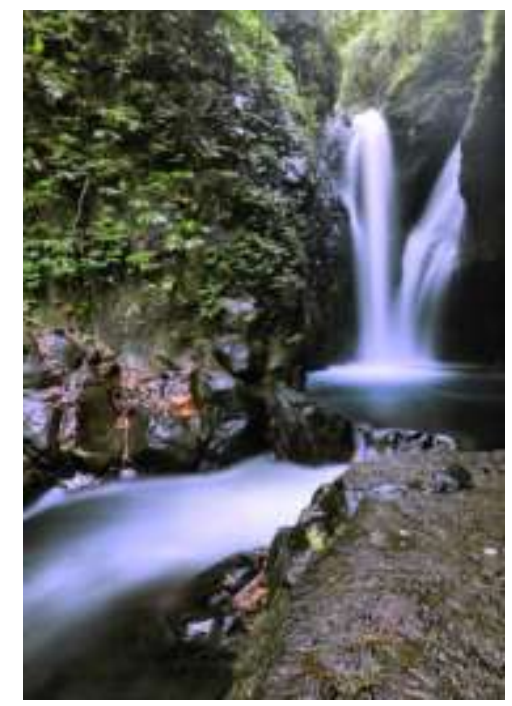

Gambar 4. Mengalir begitu saja

\section{Karya 4 Matahari Terbenam Tetap Memancarkan Kemilaunya, 2013}

Foto ini berlokasi di pantai Kuta, Kuta - Bali. Foto ini menggambarkan sebelum tenggelamnya matahari yang tetap memancarkan keindahannya, dengan diafragma yang kecil tetap memberikan ketajaman pada foto, komposisi yang digunakan adalah komposisi rule of third yang akan mendapatkan empat titik perpotongan pada langit, matahari, manusia, dan daratan yang nantinya akan mendapat daya tarik 
maksimum. Nikon D90, focal length 18mm, f/11, speed 1/320, ISO 100.

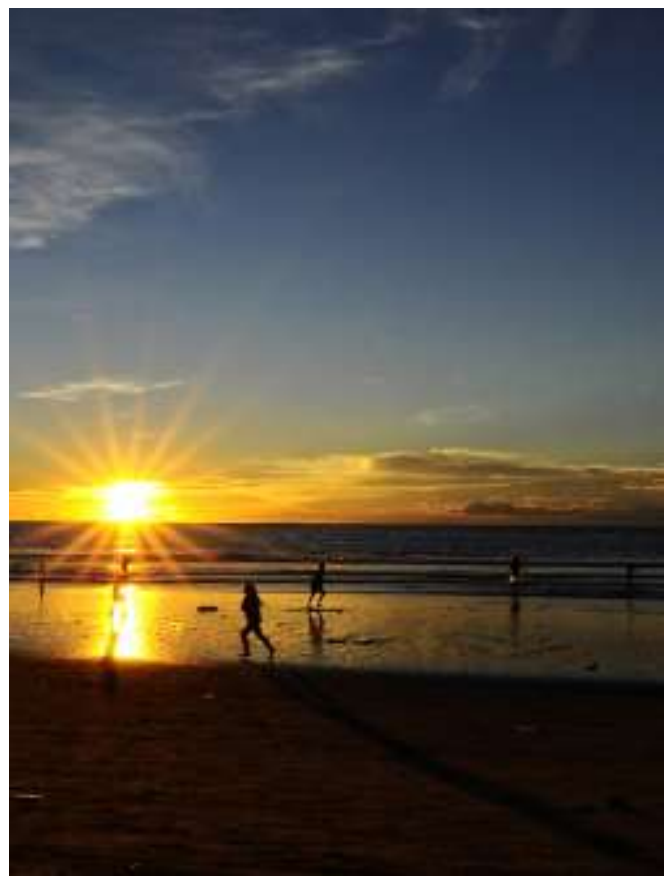

Gambar 5 Matahari terbenam tetap memancarkan kemilaunya

\section{Karya 5 Hamparan Sawah Nan Subur Menuju Pantai, 2013}

Foto ini berlokasi di persawahan Rambut Shiwi, Negara Bali. Foto ini menggambarkan pemandangan hamparan persawahan dengan komposisi garis pada objek jalanan yang menuju ke pantai untuk melihat ke jalanan hingga ujung jalanan, sehingga akan menampilkan kedalaman ruang pada foto, dengan diafragma kecil untuk mempertajam foto portrait landscape. Nikon D90, focal length $18 \mathrm{~mm}, \mathrm{f} / 11$, speed 1/125, ISO 100.

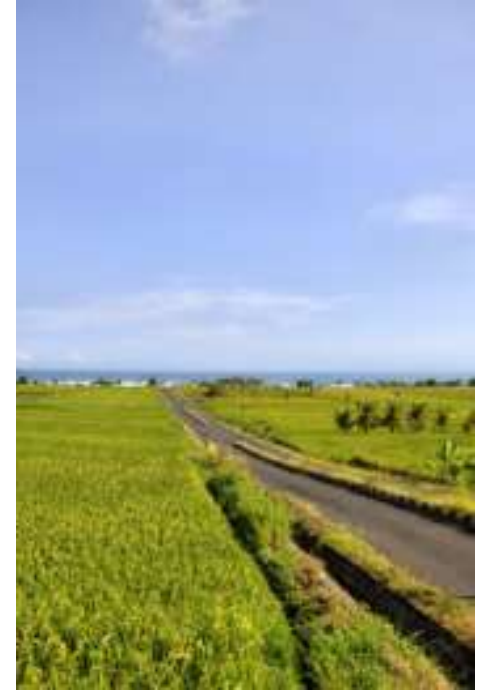

Gambar 6. Hamparan sawah nan subur menuju pantai

\section{Karya 6 Sunset Pantai Alas Pulaki,} 2013

Foto ini berlokasi di pantai Alas Pulaki, Singaraja - Bali yang menggambarkan sunset di pantai Alas Pulaki. Point of interestnya adalah langit yang memancarkan cahayanya dan focal pointnya atau pertama mata terarah adalah pada gunung. Komposisi yang digunakan rule of third yaitu pembagian garisgaris yang membentuk tiga persegi panjang sama besar baik horizontal atau vertikal. Dan menemukan empat titik perpotongan pada langit, gunung, dan laut mendapat daya tarik maksimum, dan dengan diafragma kecil akan mendapatkan ketajaman pada foto. Nikon D90, focal length $32 \mathrm{~mm}, f / 29$, speed $1 / 2$, ISO 100. 


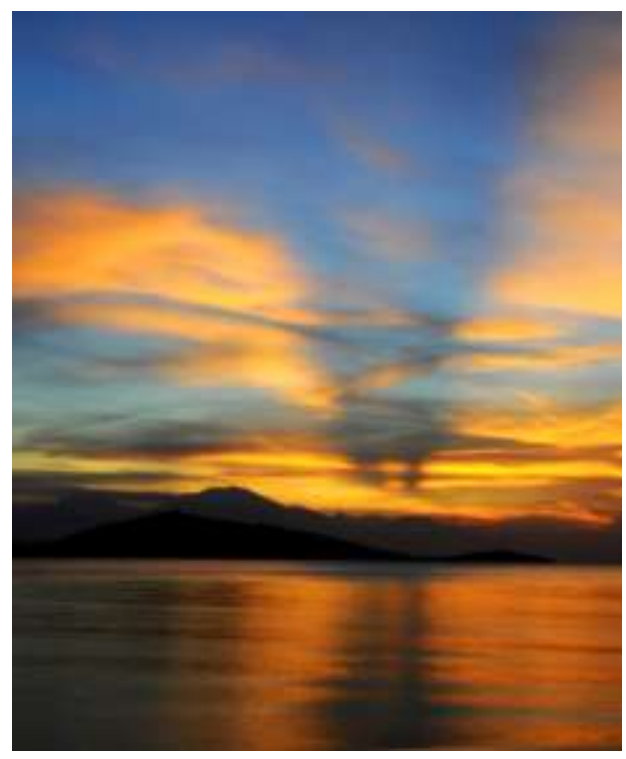

Gambar 7. Sunset pantai Alas Pulaki

Karya 7 Karang Berselimut Air, 2013

Foto ini berlokasi di pantai Dreamland, Badung - Bali yang menggambarkan sebelum matahari tenggelam dengan cuaca yang mendung. Objek karang yang berada di pinggir pantai yang terkena ombak terlihat seperti awan karena menggunakan teknik slow speed yang di bantu dengan filter ND (Neutral Density) untuk memberikan efek lebih gelap pada lensa dan pastinya akan menggunakan speed lebih rendah.

Komposisi yang digunakan adalah komposisi rule of third yaitu pembagian garis-garis yang akan membentuk tiga persegi panjang sama besar baik horizontal atau vertikal dan akan menemukan 4 titik perpotongan pada awan, karang, dan air. Nikon D90, focal length $11 \mathrm{~mm}$, f/22, speed 1.6”, ISO 100.

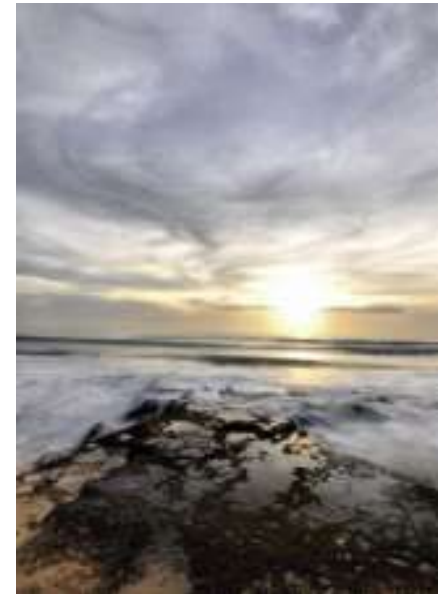

Gambar 8 Karang berselimut air

\section{Karya 8 Perahu Nelayan Pantai Sanur, 2013}

Foto ini berlokasi di pantai Sanur, Denpasar - Bali. Foto ini menggambarkan suasana sunrise dengan komposisi pattern pada perahu yang keberadaan pengulangannya dapat menimbulkan kesan harmoni dan keselarasan pada sebuah foto. Dan dengan teknik slow speed dan penggunaan filter ND (Neutral Density) yang menggambarkan air pantai yang bergerak. Nikon D90, focal length $11 \mathrm{~mm}, \mathrm{f} / 22$, speed 1', ISO 100.

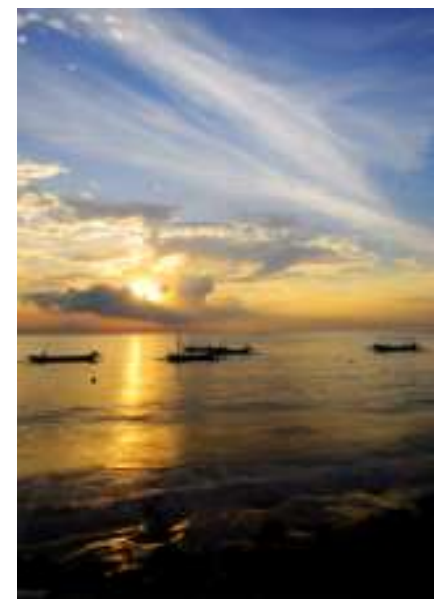

Gambar 9. Perahu nelayan Pantai Sanur 


\section{Karya 9 Terik pun Jadi, 2013}

Foto ini berlokasi di pantai Balangan, Badung - Bali. Foto ini menggambarkan pantai di sore hari yang cuacanya masih terasa panas.

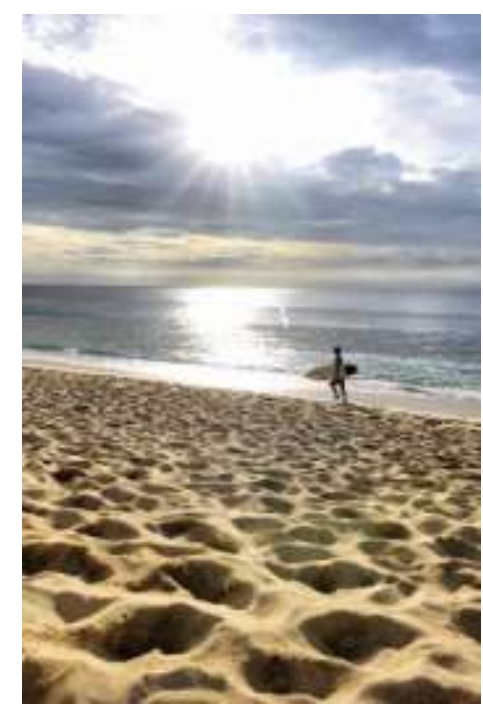

Gambar 10. Terik pun jadi

Penambahan objek manusia pada foto dapat terlihat adanya kegiatan di pantai, dan dengan komposisi pattern pada foreground pasir pantai yang menimbulkan kesan harmoni dan keselarasan pada foto, dan dengan diafragma yang kecil dapat lebih mempertajam foto pemandangan. Nikon D90, focal length $11 \mathrm{~mm}$, f/11, speed $1 / 100, \mathrm{ISO}$ 100.

\section{Karya 10 Selamat Pagi Kintamani, 2013}

Foto ini berlokasi di Kintamani - Bali. Foto ini menggambarkan hangatnya pagi di kintamani dengan pemandangan gunung Baturnya, di foto ini point of interestnya adalah matahari yang bersinar di balik ranting pohon dan focal pointnya atau pertama mata terarah adalah pada gunung.

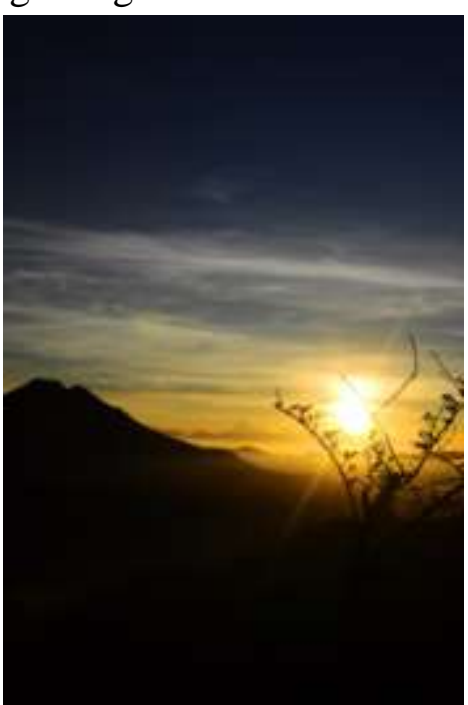

Gambar 11. Selamat pagi Kintamani

Komposisi yang digunakan pada foto ini adalah komposisi rule of third yaitu pembagian garis-garis yang akan membentuk tiga persegi panjang sama besar baik horizontal atau vertikal. Dan akan menemukan empat titik perpotongan pada langit, gunung, dan matahari bersama ranting pohon yang akan mendapat daya tarik maksimum, dan dengan diafragma kecil dapat mempertajam fotonya. Nikon D90, focal length 26mm, f/11, speed 1/250, ISO 100.

\section{Karya 11 Besar Kecilnya Menipu, 2013}

Foto ini berlokasi di pantai Pasir Putih, Karangasem - Bali. Foto ini menggambarkan point of interestnya pada batangan kayu yang berada di pinggir pantai dan focal pointnya atau pertama mata terarah pada pulau yang terlihat kecil di foto, dengan menggunakan filter CPL (Circular Polarizer) langit pada foto 
menjadi lebih biru, dan dengan diafragma kecil dapat menjadikan foto lebih tajam. Nikon D90, focal length $18 \mathrm{~mm}, \mathrm{f} / 11$, speed $1 / 80$, ISO 100.

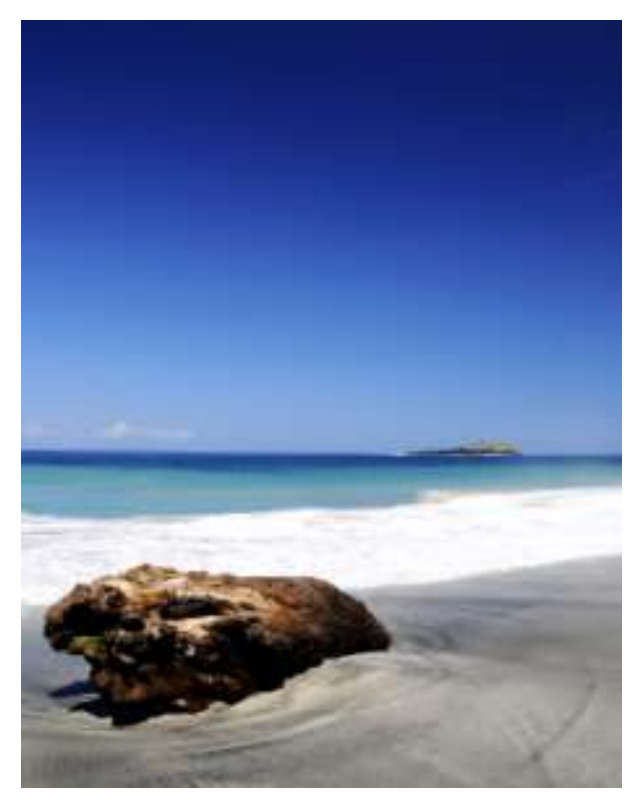

Gambar 12. Besar kecilnya menipu

\section{Karya 12. Batu-Batu Kotak \\ Menghiasi Pinggiran Pantai, 2013}

Foto ini berlokasi di pantai Alas Pulaki, Singaraja - Bali. Foto ini menggambarkan pinggiran pantai yang tidak biasa, yang biasanya di dominasi dengan pasir pantai, tetapi di pantai Alas Pulaki ini sebagian pinggiran pantainya di penuhi dengan batu-batu berbentuk kotak. Komposisi yang digunakan adalah komposisi pattern pada batu-batu kotak yang terdapat di pinggiran pantai yang menimbulkan kesan harmoni dan keselarasan pada foto, dan dengan penggunaan diafragma yang kecil dapat mempertajam hasil foto. Nikon D90, focal length $12 \mathrm{~mm}$, f/11, speed 1/60, ISO 100.

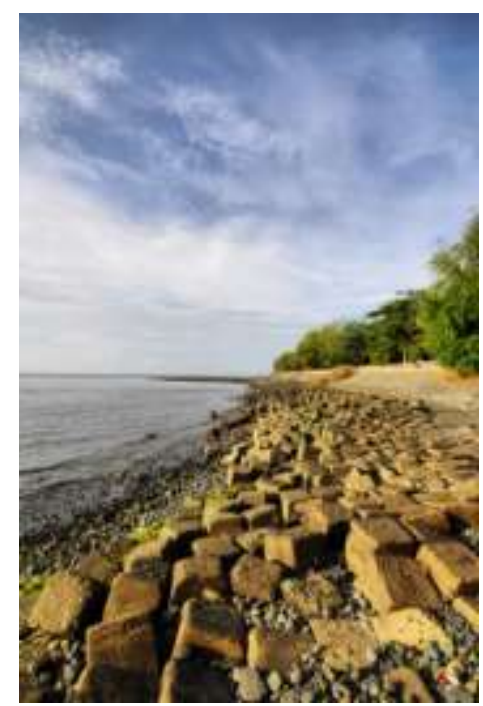

Gambar 13. Batu-batu kotak menghiasi pinggiran pantai

\section{Karya 13. Menuju Sunrise Tiba Pantai Lovina, 2013}

Foto ini berlokasi di pantai Lovina, Buleleng - Bali. Foto ini menggambarkan sebelum matahari benar-benar terlihat dipermukaan bumi, tetapi cahaya yang dipancarkannya sudah memberikan keindahan tersendiri, dengan diafragma yang kecil membuat foto menjadi terlihat lebih tajam, dan dengan komposisi framing objek utama yaitu pantai, kapal nelayan, beserta langit menjadi point of interest.

Tambahan bingkai berupa pohon terlihat jelas pada sebelah kanan foto tetapi tidak menjadi dominan membuat objek utama semakin terlihat menonjol, dan framing pohon dapat mengisi bidang foto agar tidak terlihat kosong, sehingga keseluruhan objek foto tampak lebih indah. Dengan teknik slow speed dan menggunakan filter ND (Neutral Density) membuat air 
pantai terlihat menjadi tenang. Nikon D90, focal length $22 \mathrm{~mm}, \mathrm{f} / 22$, speed 10", ISO 100.

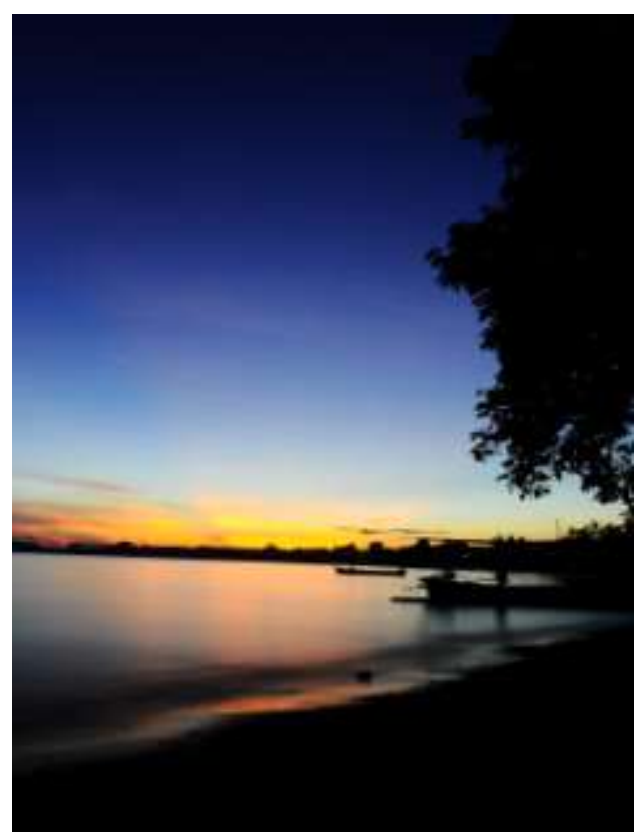

Gambar 14. Menuju sunrise tiba Pantai Lovina

\section{Karya 14. Bingkai Pura Ulun Danu, 2013}

Foto ini berlokasi di danau Bratan, Tabanan - Bali. Foto ini menggambarkan Pura Ulun Danu yang terlihat terbingkai dengan pohon di sisi kiri kanannya. Komposisi yang digunakan adalah komposisi framing yang bingkainya berupa pohon yang terlihat jelas di sisi kiri kanan pada foto dan Pura Ulun Danu yang menjadi point of interest di tengahnya, dan dengan diafragma kecil dapat lebih mempertajam foto. Nikon D90, focal length $11 \mathrm{~mm}, \mathrm{f} / 8$, speed $1 / 60, \mathrm{ISO}$ 100.

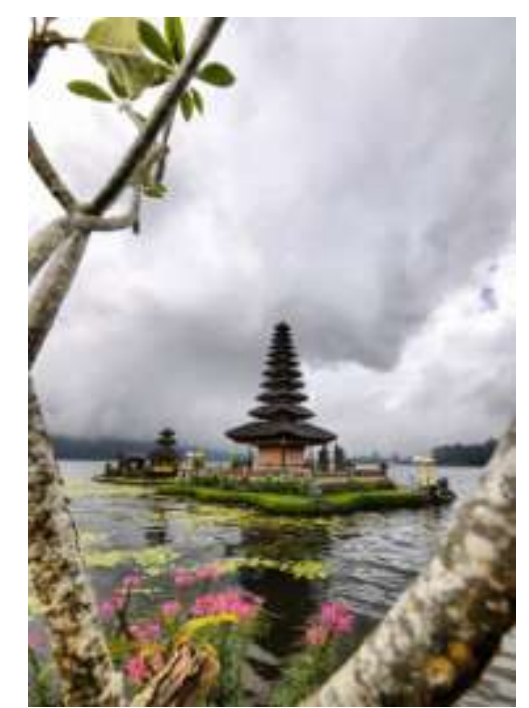

Gambar 15. Bingkai Pura Ulun Danu

\section{Karya 15. Sunrise Menemani Kami Menuju Pulang, 2013}

Foto ini berlokasi di pantai Lovina, Buleleng - Bali. Foto ini menggambarkan sunrise di pantai dan memasukkan objek perahu nelayan yang sedang dipergunakan untuk berkeliling di tengah laut untuk melihat lumba-lumba.

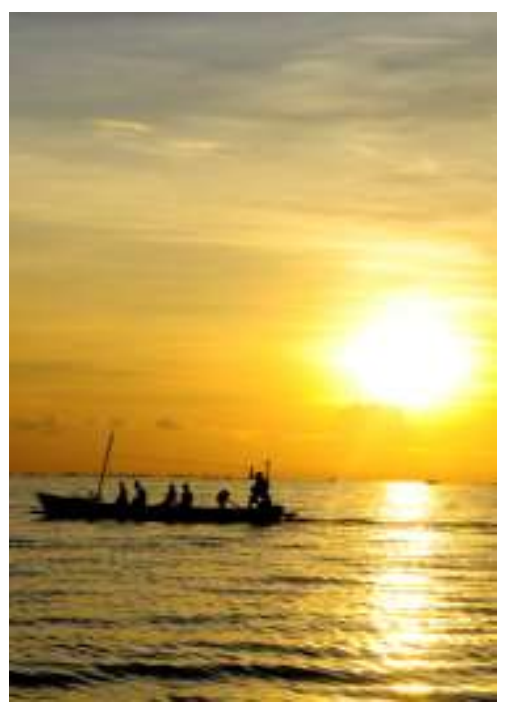

Gambar 16. Sunrise menemani kami menuju pulang 
Komposisi yang digunakan adalah komposisi rule of third yang mempertemukan 4 titik pada pembagian pada langit, matahari, laut, dan perahu nelayan, dengan diafragma yang kecil foto akan terlihat lebih tajam. Nikon D90, focal length 40mm, f/11, speed 1/160, ISO 100.

\section{Karya 16. Sendiri Juga Indah, 2013}

Foto ini berlokasi di persawahan Rambut Shiwi, Negara Bali. Foto ini menggambarkan pemandangan dengan penambahan objek pohon di antara persawahan, yang menjadikan point of interestnya pohon tersebut.

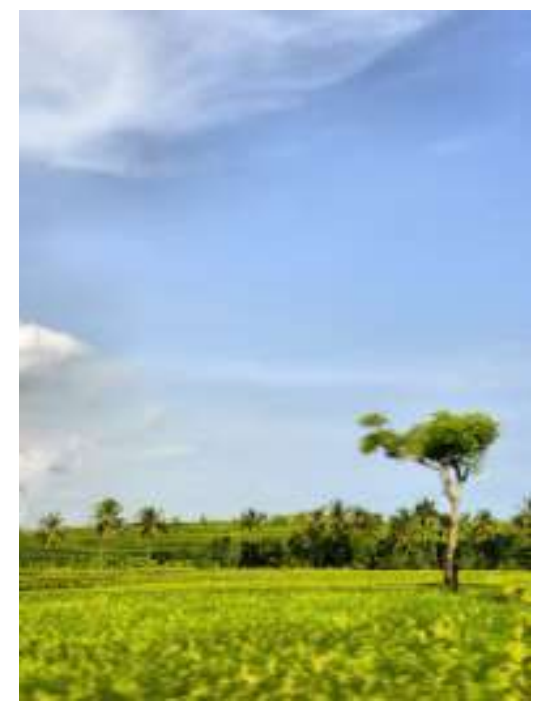

Gambar 17 Sendiri juga indah

Komposisi yang digunakan adalah komposisi rule of third yang didapatkan empat titik perpotongan yang di salah satu titik perpotongan terdapat objek yang menjadi point of interest ditempatlkan dan dengan diafragma kecil akan mendapatkan foto portrait landscape lebih tajam.
Nikon D90, focal length 35mm, f/11, speed 1/125, ISO 100.

\section{Karya 17. Mancing di Kala Senja,} 2013

Foto ini berlokasi di pantai Alas Pulaki, Singaraja - Bali. Foto ini menggambarkan pantai di senja hari, di mana matahari akan terbenam beberapa menit lagi, dan dengan penambahan aktifitas manusia di sekitar lokasi akan memperindah foto yang akan memberikan kesan berbeda juga jika ada foto portrait landscape dengan lokasi yang sama. Komposisi yang digunakan adalah komposisi rule of third yang didapatkan empat titik perpotongan yang menjadikan matahari, langit, manusia, dan karang yang akan mendapat daya tarik maksimum, dan dengan diafragma kecil dapat mempertajam fotonya. Nikon D90, focal length $11 \mathrm{~mm}, \mathrm{f} / 11$, speed 1/400, ISO 100.

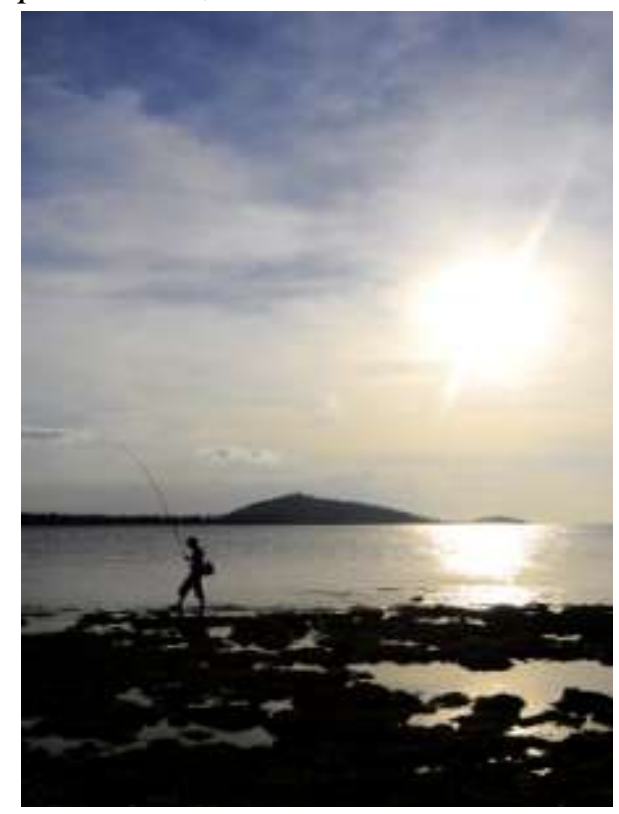

Gambar 18. Mancing di kala senja 


\section{Karya 18. Hamparan Karang Pantai Padang-Padang, 2013}

Foto ini berlokasi di pantai Padang-Padang, Badung - Bali. Foto ini menggambarkan karang yang terdapat di pinggir pantai. Dengan menggunakan diafragma yang kecil ruang tajam foto akan semakin luas, pada foto ini tidak terpaku pada aturan komposisi yang ada. Foto ini lebih memilih melihat dengan keindahan yang dirasa oleh penulis. Nikon D90, focal length $11 \mathrm{~mm}, \mathrm{f} / 8$, speed 1/100, ISO 100.

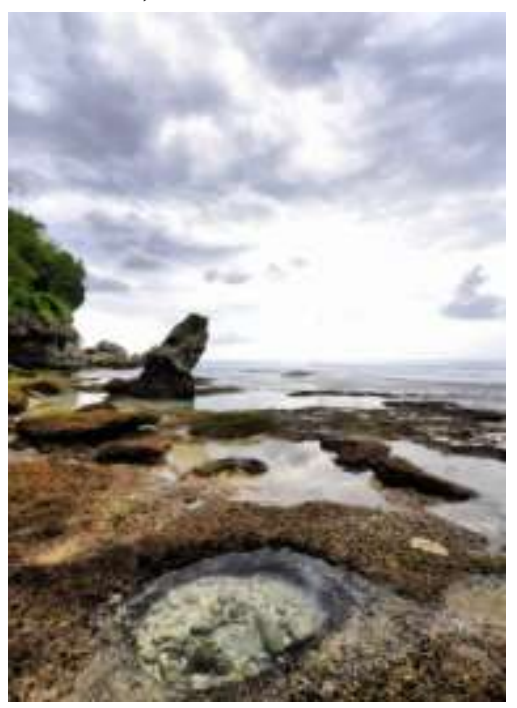

Gambar 19. Hamparan karang Pantai

Padang-Padang

\section{Karya 19. Di Balik Awan, 2013}

Foto ini berlokasi di Kintamani

- Bali. Foto ini menggambarkan sunrise di pagi hari, dengan point of interestnya matahari, dengan diafragma kecil ketajaman foto akan lebih luas dan komposisi yang digunakan adalah komposisi garis yang pengulangannya terlihat jelas pada awan-awan. Nikon D90, focal length $90 \mathrm{~mm}, \mathrm{f} / 11$, speed $1 / 80$, ISO 100.

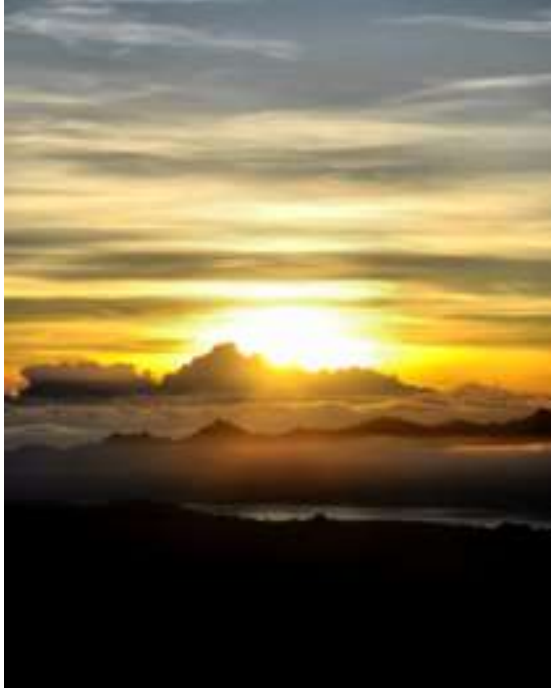

Gambar 20. Di balik awan

\section{PENUTUP}

Simpulan penelitian ini adalah Pertama, bisa dikatakan bahwa dalam komposisi yang lebih detail terlihat dalam hasil foto landscape adalah foto pada portrait landscape, karena kepadatan komposisi portrait yang ditampilkan oleh portrait landscape menjadikan foto terlihat jelas komposisi yang dipakainya. Pemandangan alam pada komposisi portrait landscape keindahan alamnya tetap terjaga.

Kedua, fotografi landscape menjadi lebih menantang dengan adanya komposisi portrait landscape. Bisa dibayangkan dalam fotografi landscape kebanyakan orang memotret dengan format horizontal yang menampilkan pemandangan alam yang seluas-luasnya menjadi hanya memotret sebagian atau setengah dari format horizontal. Dengan format yang sempit tidak bisa hanya memotret dengan sesuka hati saja, tetapi harus mempunyai rasa yang kuat untuk merasakan sisi 
mana keindahan itu dapat di foto dalam sudut sempit portrait landscape. Hanya sebagian orang yang mencoba portrait landscape dalam memotret pemandangan alam, kebanyakan orang tetap memakai format horizontal dalam landscape untuk menjelaskan pengertian landscape.

Ketiga, fotografi landscape tidak hanya sekedar menampilkan luasnya pemandangan alam sekitar agar terlihat indah dan menarik para wisatawan untuk datang ke lokasi tersebut, dengan portrait landscape pun pemandangan alam yang luas dijadikan pemandangan yang hanya setengah dari format horizontal juga dapat memberikan hasil yang indah dan menarik para wisatawan untuk datang ke lokasi.

\section{DAFTAR RUJUKAN}

Kelby, Scott. (2012), The Digital Photography Book, PT. Serambi Ilmu Semesta, Jakarta.

Noel \& Yoels. (2013), Wow Tips \& Trik Fantastik Bikin Foto Unik dengan Kamera Saku dan DSLR, MediaKom.

Paulus, Edison. (2013), Buku Saku Fotografi Landscape, PT. Elex Media Komputindo, Jakarta.

Sukarya, Deniek G. (2009), Kiat Sukses Deniek G. Sukarya dalam Fotografi dan Stok Foto, PT. Sukarya \& Sukarya Pandetama, Jakarta.

Sugiarto, Atok. (2006), Jurus Memotret Objek Bergerak, PT.
Gramedia Pustaka Utama, Jakarta.

Yasin, Yadi. (28 Desember 2009/13.22), Portscape = Portrait Landscape.

http://www.fotografer.net/forum/ forum.view.php?id=3194219522 